\title{
Perfectionism mediated the relationship between brain structure variation and negative emotion in a nonclinical sample
}

\author{
Di Wu ${ }^{1,2} \cdot$ Kangcheng Wang ${ }^{1,2} \cdot$ Dongtao Wei ${ }^{1,2} \cdot$ Qunlin Chen ${ }^{1,2} \cdot$ Xue Du ${ }^{1,2}$. \\ Junyi Yang ${ }^{1,2}$. Jiang Qiu ${ }^{1,2}$
}

Published online: 2 December 2016

(C) Psychonomic Society, Inc. 2016

\begin{abstract}
In maladaptive respects, perfectionism reflects an individual's concern over making mistakes and doubting the quality of his or her own actions excessively, which would affect one's emotion. However, little is known about the neural mechanisms associated with the perfectionism and negative affect. In this study, voxel-based morphometry was performed to identify the brain regions underlying individual differences in perfectionism, which was measured by the Chinese Frost Multidimensional Perfectionism Scale (CFMPS), in a large sample of nonclinical young adults. Our results showed that the two subdimensions of the perfectionism, concern over mistakes (CM) and doubts about actions (DA), were both positively correlated with the selfreported anxiety and depression as well as the gray matter volume (GMV) in the anterior cingulate cortex (ACC), a pivotal brain region in cognitive control, affective state, and regulation. Moreover, CM, DA, and organization scores were respectively correlated with distributed brain regions involved in multiple cognitive and emotion processes. Our results furthermore revealed that the score of DA acted a mediational mechanism underlying the relationship between the GMV of ACC and self-rating negative affect (anxiety and depression). Taken together, these results might suggest the neuroanatomical basis of perfectionism and the association among the perfectionism, negative emotion, and brain architecture. This
\end{abstract}

Di Wu and Kangcheng Wang contributed equally to this work.

Jiang Qiu

qiuj318@swu.edu.cn

1 Key Laboratory of Cognition and Personality (SWU), Ministry of Education, Chongqing, China

2 Department of Psychology, Southwest University (SWU), No. 2, Tiansheng Street, Beibei district, Chongqing 400715, China study emphasized that perfectionism could play a crucial role in the arousal of negative affect.

Keywords Perfectionism · Anxiety · Depression · Anterior cingulate cortex $\cdot$ Voxel-based morphometry

Perfectionism is characterized by an individual setting excessively high performance standards, worrying about making mistakes, and doubting about actions. Numerous behavioral studies confirmed that perfectionism, especially maladaptive perfectionism, has a close relationship with some negative outcomes and mental vulnerabilities, such as suicidal behaviors, stress, obsessive-compulsive disorder, eating disorders (Bachner-Melman et al., 2007; Chang, Ivezaj, Downey, Kashima, \& Morady, 2008; Enns et al., 2002; Frost, Heimberg, Holt, Mattia, \& Neubauer, 1993; Frost, Marten, Lahart, \& Rosenblate, 1990; Lee et al., 2009; Lindner, Fichter, \& Quadflieg, 2013; O’Connor \& Nock, 2014; O'Connor, Rasmussen, \& Hawton, 2010; Sassaroli, et al., 2008; Uzun Ozer, O’Callaghan, Bokszczanin, Ederer, \& Essau, 2014; Wheeler, Blankstein, Antony, McCabe, \& Bieling, 2011; Wu \& Cortesi, 2009), and so forth. Furthermore, previous studies suggested that maladaptive perfectionism might be an underlying risk factor for the vulnerability of anxiety and depression (Besharat, Issazadegan, Etemadinia, Golssanamlou, \& Abdolmanafi, 2014; Bieling, Summerfeldt, Israeli, \& Antony, 2004; Enns et al., 2002; Frost et al., 1990; Frost et al., 1993; Wheeler et al., 2011; Uzun Ozer et al., 2014; Wu \& Cortesi, 2009).

Various attempts have been made to define the construct of perfectionism. Early theories and research viewed perfectionism as a unidimensional construct and developed scales with a limited number of items. For example, Burns (1980) considered perfectionism as "those whose standards 
are high beyond reach or reason, people who set unremittingly impossible goals" (p. 34) and developed a perfectionism scale with only 10 items. Garner and his colleagues also designed a unidimensional perfectionism subscale in their Eating Disorder Inventory (Garner, Olmstead, \& Polivy, 1983). However, subsequent research indicated that the perfectionism should be a multidimensional cognitive-personality construct, including both personal and social components. In addition, some of dimensions should be deemed to be adaptive, linking with positive outcomes, such as organization and selforiented perfectionism, and others should be maladaptive, linking with distress or negative outcomes, including concern over mistakes, doubts about actions, and socially prescribed perfectionism (Chang et al., 2008; Enns et al., 2002; Frost et al., 1993; Frost et al., 1990; Hewitt, Flett, TurnbullDonovan, \& Mikail, 1991; Wheeler et al., 2011). According to these views, Frost and his colleagues developed the Multidimensional Perfectionism Scale (FMPS), which is one of the most commonly used and well-validated measures. It employed a six-component model, comprising concern over mistakes (CM), personal standards (PS), parental expectations (PE), doubts about actions (DA), parental criticism (PC), and organization (OR) (Frost et al., 1993; Frost et al., 1990).

Some behavioral studies revealed that there were close association between CM, DA, and anxious or depressive symptoms (Enns et al., 2002; Frost et al., 1993; Frost et al., 1990; Hewitt et al., 1991; Saboonchi \& Lundh, 1997; Shafran \& Mansell, 2001; Stöber, 1998; Uzun Ozer et al., 2014; Wheeler et al., 2011). Individuals with high perfectionism often misinterpreted mistakes as failure and worry about losing others' respect following failure, or excessively doubt their own ability to accomplish tasks and thus show no confidence in their own performance. Subsequently, such worry and doubt would trigger and maintain their anxious or depressive symptoms (Frost et al., 1990). In both healthy and clinical samples (Besharat et al., 2014; Bieling et al., 2004; Cheng et al., 2015; Egan, Wade, \& Shafran, 2011), perfectionism can be confirmed as a predictive cognitive-personality risk factor of anxious and depressive symptoms. Studies on treatment for mood disorders, including cognitive-behavioral therapy and some other treatments in major depressive disorder, suggested perfectionism could be considered a crucial factor and would affect therapeutic outcomes to some extent (Blatt, Quinlan, Pilkonis, \& Shea, 1995; Blatt, Zuroff, Bondi, Sanislow, \& Pilkonis, 1998; Zuroff et al., 2000). Thus, understanding the brain neural correlates underlying perfectionism would be particularly essential to the generation and cognitive process of negative affect.

To date, there have been few studies about the brain structure bases of perfectionism and its relation to negative emotion, whereas much of the literature has discussed the brain regions and networks of negative emotion, such as anxiety (Sylvester et al., 2012). Maladaptive perfectionism would be commonly accompanied by high trait anxiety (Kawamura, Hunt, Frost, \& DiBartolo, 2001). Research on individuals with high trait anxiety uncovered their impoverished prefrontal recruitment in response to processing a competition task (Bishop, 2009). By using other tasks, like the two-choice prediction task, individuals with high trait anxiety showed abnormal activation in the anterior cingulate cortex (ACC), mainly the dorsal ACC (dACC) and medial prefrontal cortex (PFC). Results also revealed that there was a positive correlation between activation in dACC, medial PFC, and trait anxiety (Paulus, Feinstein, Simmons, \& Stein, 2004). Diffusion tensor imaging studies, from another perspective, showed that fibers between the PFC and the limbic system could predict trait anxiety as well (Eden et al., 2015; Kim \& Whalen, 2009).

Moreover, previous studies agreed with the viewpoint that maladaptive perfectionists would have emotions associated with higher order cognitive dysfunctions, such as rumination (Blankstein \& Lumley, 2008; Flett, Madorsky, Hewitt, \& Heisel, 2002; Harris, Pepper, \& Maack, 2008), and suffer from deficits in emotion regulation (Aldea \& Rice, 2006; Rudolph, Flett, \& Hewitt, 2007). Rumination, a coping style with unintentionally repetitive thinking about one's negative emotions, was associated with medial, dorsolateral PFC (DLPFC), and ACC in both normal and depressive populations (Cooney, Joormann, Eugene, Dennis, \& Gotlib, 2010; Wang et al., 2015). For emotion regulation, it has been proved as a consequence from multiple brain regions, recruiting the crucial engagement of the PFC, ACC, and connectivity with regions from the limbic system (Eden et al., 2015; Kohn et al., 2014; Morawetz, Bode, Baudewig, Kirilina, \& Heekeren, 2016). In essence, ACC is believed to play an important role in control, avoidance, error-related activity, affective state, and regulation (Bush, Luu, \& Posner, 2000; Giuliani, Drabant, \& Gross, 2011; Kohn et al., 2014; Mohanty et al., 2007; Shackman et al., 2011; Stevens, Hurley, \& Taber, 2011). A comprehensive meta-analytical study demonstrated emotion involved in other brain regions, including the inferior frontal gyrus (IFG), presupplementary motor area (pSMA), superior temporal gyrus (STG), and angular gyrus (Kohn et al., 2014), which could be supported by other empirical evidence as well (Morawetz, et al., 2016).

Besides, clinical research on patients with maladaptive perfectionism also uncovered abnormalities in PFC and ACC (Egan et al., 2011; Rhéaume, Freeston, Dugas, Letarte, \& Ladouceur, 1995; Shafran \& Mansell, 2001). For instance, anorexia nervosa patients with a relentless perfectionism showed the structural abnormality and dysfunction of the ACC, cingulate gyrus, and superior frontal gyrus (Mühlau et al., 2007; Rothemund et al., 2011). Obsessive-compulsive disorder patients also exhibited the brain morphological and functional abnormalities in PFC and ACC, regions engaged in conflict monitor error processing (Ducharme, Dougherty, \& Drevets, 2016; Fitzgerald et al., 2005; Graybiel \& Rauch, 
2000; Van Veen \& Carter, 2002). These results might suggest the underlying roles of ACC and PFC in perfectionism as well.

In summary, the relationship among individual differences in perfectionism, brain structure, and negative affect in nonclinical samples remains unclear. Therefore, the aim of this study was to investigate the association of the brain regions and perfectionism with anxious and depressive emotion in a large, nonclinical sample of Chinese undergraduate students $(N=161)$.We first supposed that some subdimensions of perfectionism had significant correlations with the scores of the Self-Rating Anxiety Scale (SAS) and the Self-Rating Depression Scale (SDS) in our large nonclinical sample, respectively. Second, we hypothesized that the brain's structural variations for perfectionism were widespread in regions related to emotion-related cognitive processes, mainly the PFC (e.g., DLPFC, IFG), ACC, insula, SMA, STG, and angular gyrus (Kohn et al., 2014; Morawetz et al., 2016). Third, given the association between maladaptive perfectionism and negative affect (Enns et al., 2002; Frost et al., 1990; Uzun Ozer et al., 2014; Wheeler et al., 2011), the crucial role of the PFC and ACC in cognitive control, emotional processing, and regulation (Buhle et al., 2014; Bush et al., 2000; Giuliani, Drabant, \& Gross, 2011; Kohn et al., 2014; Morawetz et al., 2016; Shackman et al., 2011; Stevens et al., 2011), we hypothesized that perfectionism would be able to mediate the relationship between the PFC and negative affect. By using imaging data in vivo, we are able to reveal the structural correlates of individual differences in perfectionism as well as the association among perfectionism, brain structures, and negative affect. Furthermore, it would provide fundamental evidence for emotional processing and regulation.

\section{Method}

\section{Participants}

A total of 161 right-handed healthy volunteers (92 women and 69 men; ages $17-26$ years, mean age $=19.98$ years, $S D=$ 1.13 years) participated in this study. It was a part of our ongoing project exploring the associations among brain structures and function, creativity, and mental health (http://www. qiujlab.com/resource). All subjects were university students who were recruited from the local community in the Southwest University, China. To confirm typical development, all participants had normal or corrected-tonormal vision and were screened by self-reported questionnaires before scanning. Thus, participants who had a history of psychiatric or neurological disorders, received mental health treatment, or took psychiatric medications were excluded.

The Ethics Committee of Southwest University formally approved the research protocol. All participants gave written informed consent, and we also obtained written informed consent from the youngest participant's (age 17 years) guardian, who was her college instructor. The Brain Imaging Center Institutional Review Board of Southwest University approved this study, and the experiment procedure was carried out in accordance with the Declaration of Helsinki principles. All participants were paid for their participation.

\section{Measuring individual anxiety and depression}

The SAS was selected to assess the level of anxiety. This 20item self-rating instrument included 15 somatic and five affective symptoms (Zung, 1971). Participants rated each item on a 4-point Likert scale, ranging from 1 (none or a little of the time) to 4 (most of the time). Examples of SAS items are as follows: "I feel more nervous and anxious than usual" (Anxiousness); "My arms and legs shake and tremble" (Tremors); "I feel weak and get tired easily" (Easy fatigability, weakness); "I can feel my heart beating fast" (Palpitation); "I have nightmares" (Nightmares). What's more, SAS demonstrated good reliability, with the initial split-half reliability being 0.71 . It has been employed in both clinical and nonclinical participants (Olatunji, Deacon, Abramowitz, \& Tolin, 2006; Wei et al., 2015; Zung, 1971). It also was used in previous studies on anxiety and perfectionism (Balazs et al., 2013; Julal, 2013; Pravettoni, Cropley, Leotta, \& Bagnara, 2007; Sevlever \& Rice, 2010; Shahid et al., 2016; Wei et al., 2015; Wu \& Wei, 2008; Zi \& Zhou, 2007). In this study, the Cronbach's alpha coefficient for internal reliability in our sample was 0.79 .

We used 20 items in the SDS to assess depression in each participant. The SDS is a self-report assessment tool, with each response using a 4-point scale, ranging from 1 (none or a little of the time) to 4 (most of the time). It divided those common characteristics of depression into three parts: pervasive affect, physiological equivalents or concomitants, and psychological concomitants (Zung, 1965). Furthermore, it contained items as follows: "I feel down-hearted and blue" (Depressed, sad, and blue in Pervasive affect), "I still enjoy sex" (Sex: decreased libido in Rhythmic Disturbances of Physiological equivalents), "I get tired for no reason" (Musculoskeletal: fatigue in Other Disturbances of Physiological equivalents), "I find myself restless and can't keep still" (Agitstion in Psychomotor activities in Psychological concomitants), "I am more irritable than usual" (Irritability in Ideational in Psychological concomitants). Ten items were worded symptomatically positive and another 10 symptomatically negative. The SDS also demonstrated adequate reliability and validity (Thurber, Snow, \& Honts, 2002). The psychometric evaluation revealed that the SDS correlated well with the Hamilton Rating Scale for Depression and the Beck Depression Inventory (Biggs, Wylie, \& Ziegler, 1978; 
Dobson, 1985; Davies, Burrows, \& Poynton, 1975; Meites, Lovallo, \& Pishkin, 1980). Recent research also reported that this scale had an adequate internal reliability and was converged with other self-report assessments of depression, such as the Depression Adjective Check List, the Brief Symptom Inventory, and the Major Depression Scale (Thurber et al., 2002). Therefore, the SDS has also been used in research about depression and perfectionism (Di Schiena, Luminet, Philippot, \& Douilliez, 2012; Julal, 2013; Xia, Ding, Hollon, \& Fan, 2012; Zi \& Zhou, 2007). In our sample, the Cronbach's alpha coefficient for internal reliability was 0.85 .

\section{Measuring individual perfectionism}

Perfectionism was assessed by using a self-report scale, the Chinese Frost Multidimensional Perfectionism Scale (CFMPS; Zi \& Zhou, 2007), which was revised from one of the most widely used multidimensional perfectionism measures-FMPS (Frost et al., 1990). Compared to Hewitt and Flett's Multidimensional Perfectionism Scale (HMPS), FMPS reflected a more global characteristic that contained elements of both self-oriented and socially prescribed perfectionism (Frost et al., 1993). Besides, the scale described more specific characteristics, which consisted of six dimensions (Frost et al., 1990). Finally, a study, which compared the two generally used scales, suggested that components from FMPS were more closely related to negative affect compared with items in HMPS (Frost et al., 1993). Thus, FMPS was selected in this study to investigate the neural correlates of perfectionism and the association with negative affect.

In the Chinese version, the dimension of parental criticism (PC) was combined into parental expectations (PE). Thus, CFMPS consisted of five dimensions: CM, PS, PE, DA, and OR. Example items from the questionnaire were as follows: "If I fail at work/school, I am a failure as a person" (CM); "If I do not set the highest standards for myself, I am likely to end up a second-rate person" (PS); "My parents set very high standards for me" (PE); "I usually have doubts about the simple everyday things I do" (DA); and "Organization is very important to me" (OR). For each item, participants were asked to indicate to what extent they agreed or disagreed with the given items on a 5-point Likert scale, ranging from 1 (strongly disagree) to 5 (strongly agree), with the higher scores indicating the greater level of perfectionism (Chang et al., 2008). Previous studies have shown that the scale possessed adequate reliability, construct validity, and criterion-related validity with other constructs such as the SAS, SDS, Symptom Checklist 90, the Fear of Negative Evaluation Scale, and the Self-Esteem Scale in Chinese populations (Zi \& Zhou, 2007). In this study, the scale demonstrated an adequate internal reliability (Cronbach's $\alpha=0.74$ to 0.82 ).

\section{Magnetic resonance imaging (MRI) data acquisition}

Whole-brain anatomical images were acquired on a 3.0-T Siemens Trio MRI scanner (Siemens Medical, Erlangen, Germany). High-resolution T1-weighted anatomical images were acquired using a magnetization-prepared rapid gradient echo sequence (repetition time $=1,900 \mathrm{~ms}$; echo time $=$ $2.52 \mathrm{~ms}$; inversion time $=900 \mathrm{~ms}$; flip angle $=9$ degrees; resolution matrix $=256 \times 256$; slices $=176$; thickness $=$ $1.0 \mathrm{~mm}$; voxel size $=1.0 \times 1.0 \times 1.0 \mathrm{~mm}^{3}$ ).

\section{Voxel-based morphometry (VBM) analysis}

All structural data images were preprocessed using the SPM8 software package (Wellcome Department of Cognitive Neurology, London, UK; www.fil.ion.ucl.ac.uk/spm) implemented in MATLAB 2009b (MathWorks Inc., Natick, MA, USA). First, each subject's MR image was displayed in SPM8 to screen for monitor artifacts or gross anatomical abnormalities. The reorientation of each structural image was further set to the anterior and posterior commissure manually for better registration. Then, via the new segmentation in SPM8, the images were segmented into gray matter (GM) and white matter (WM). Subsequently for registration, normalization and modulation, we performed Diffeomorphic Anatomical Registration Through Exponentiated Lie (DARTEL) algebra (Ashburner, 2007). After that, the image intensity of each voxel was modulated by the Jacobian determinants to ensure that regional differences in the absolute amount of GM were conserved. Moreover, registered images were transformed to Montreal Neurological Institute (MNI) space. Ultimately, the modulated images (GM images) were smoothed with an 8-mm full-width at half-maximum Gaussian kernel to increase the signal-tonoise ratio.

\section{Statistical analysis}

A multiple linear regression analysis was conducted to identify regions where gray matter volume (GMV) was associated with individual differences in the subdimension scores of perfectionism, respectively, at the whole-brain level. To control for possible confounding variables, age, gender, and global volumes of GM were entered as covariates of no interest into the regression model. Meanwhile, we also applied the explicit mask achieved by the Masking Toolbox in SPM8 to restrict the result within gray and white matter (http://www0.cs.ucl.ac. uk/staff/g.ridgway/masking/; Ridgway et al., 2009; Zhu, Zhang, \& Qiu, 2013). For the whole-brain analyses, the cluster-level statistical threshold was set at $p<.05$, and corrected at the nonstationary cluster correction (http://www. fmri.wfubmc.edu/cms/software\#NS; Hayasaka, Phan, Liberzon, Worsley, \& Nichols, 2004) with an underlying 
voxel level of $p<.005$, which has been safely applied to VBM data in some research (Hayasaka et al., 2004; Lewis, Kanai, Rees, \& Bates, 2014; Li, et al., 2014; Qiao et al., 2013; Wei et al., 2015; Zhu et al., 2013). Given brain regions with a strongly priori hypothesis, the statistical significance level was set at $p<.05$ with small volume correction (SVC) in regions of interests (ROIs), corrected at family-wise error (FWE), and all ROIs were constructed from WFU Pick Atlas software (http://www.fmri.wfubmc.edu/cms/software\#PickAtlas; Maldjian, Laurienti, \& Burdette, 2004; Maldjian, Laurienti, Kraft, \& Burdette, 2003).

Furthermore, we also defined the significant region (ACC, see VBM results) as a ROI through the xjview toolbox (http://www.alivelearn.net/xjview/). Then, the REX Toolbox (http://web.mit.edu/swg/software.htm) was used to extract the regional GMV (rGMV) of the ACC from each participant. We finally calculated the relationship between the ACC and DA score by using SPSS 16.0 software. Results with $p<.05$ (uncorrected) were considered statistically significant in these analyses.

\section{Results}

\section{Behavioral results}

Table 1 depicts the demographics and the characteristics of all questionnaires. As indicated in Table 1, CM was significantly positively correlated with SAS $(r=.513, p<.001)$ and with SDS $(r=.507, p<.001)$. Meanwhile, DA also had a significant positive relationship with SAS $(r=.468, p<.001)$ and SDS $(r=.442 ; p<.001)$. For the other three subdimensions, OR was both negatively correlated with SAS $(r=-.197, p=$ $.013)$ and with SDS $(r=-.275, p<.001)$. PS, however, was only positively correlated with SAS significantly $(r=.206, p=$
.009). All of the correlation analyses were conducted controlling for gender and age.

\section{VBM results}

We identified positive correlations between the $\mathrm{CM}$ score and rGMV in the right ACC (peak voxel of MNI: $x=14, y=25, z$ $=24 ; t=3.78$ ), MCC (peak voxel of MNI: $x=10, y=-5, z=$ $38 ; t=3.74$ ), and insula (peak voxel of MNI: $x=46, y=-3, z$ $=5 ; t=3.23$ ), and the left angular gyrus (peak voxel of MNI: $x$ $=-44, y=-62, z=39 ; t=3.46$ ), the left STG (peak voxel of MNI: $x=-48, y=0, z=0 ; t=3.32$ ) surviving with SVC in the ROIs (FWE; see Table 2).

Multiple regression analysis, with the GMV as dependent variables and DA score as independent variable, revealed a positive correlation of DA score with rGMV in the right cluster mainly located in the ACC (peak voxel of MNI: $x=2, y=$ $39, z=26 ; t=3.78$ ) corrected at the non-stationary cluster correction with an underlying voxel level of $p<.005$ (see Fig. 1 and Table 2), the left cluster spread in the triangular part of inferior frontal gyrus (peak voxel of MNI: $x=-38, y=33, z$ $=21 ; t=3.32$ ) and SMA (peak voxel of MNI: $x=-10, y=3, z$ $=48 ; t=3.88$ ). In addition, DA had a negative association with left insula (peak voxel of MNI: $x=-28, y=24, z=11 ; t=$ 3.78) and the right IFG (peak voxel of MNI: $x=49, y=32, z=$ $-3 ; t=3.76$; peak voxel of MNI: $x=49, y=30, z=-6 ; t=$ 4.05), with SVC in the ROIs (FWE; see Table 2).

Besides, with the SVC in the ROI (FWE), we found that the score of OR was positively correlated with the left IFG (peak voxel of MNI: $x=-45, y=31, z=-3 ; t=4.02$ ) (see Table 2).

\section{Mediation analysis}

At the whole-brain level, partial correlation analyses revealed not only a positive association between the DA score and SAS

Table 1 Descriptive statistics $(n=161)$

\begin{tabular}{|c|c|c|c|c|c|}
\hline Variables & Mean $( \pm S D)$ & Normative data & Range & Association with SAS & Association with SDS \\
\hline Age (years) & $19.98( \pm 1.13)$ & - & $17-26$ & - & - \\
\hline $\mathrm{CM}$ & $12.68( \pm 4.58)$ & $11.5( \pm 4.9)$ & $6-24$ & $.513^{* * * *}$ & $.507^{* * * *}$ \\
\hline DA & $12.33( \pm 3.38)$ & $12.2( \pm 3.8)$ & $4-20$ & $.468^{* * * *}$ & $.442^{* * * *}$ \\
\hline OR & $23.85( \pm 3.79)$ & $24.4( \pm 4.8)$ & $13-30$ & $-.197^{*}$ & $-.275^{* * * *}$ \\
\hline $\mathrm{PE}$ & $14.42( \pm 4.56)$ & $13.6( \pm 5.1)$ & $5-25$ & .141 & .150 \\
\hline PS & $18.14( \pm 4.68)$ & $18.7( \pm 5.2)$ & $7-29$ & $.206^{* *}$ & .087 \\
\hline SAS & $33.83( \pm 6.46)$ & $29.79( \pm 10.07)$ & $20-58$ & - & $.791^{* * * *}$ \\
\hline SDS & $36.55( \pm 8.02)$ & $33.46( \pm 8.55)$ & $21-58$ & $.791^{* * * *}$ & - \\
\hline
\end{tabular}

Note $\mathrm{CM}=$ subdimension of the perfectionism, concern over mistakes; $\mathrm{DA}=$ subdimension of the perfectionism, doubts about actions; OR = subdimension of the perfectionism, organization; $\mathrm{PE}=$ subdimension of the perfectionism, parental expectations; PS = subdimension of the perfectionism, personal standards; SAS = Self-Rating Anxiety Scale; SDS = Self-Rating Depression Scale. The normative data were from Chinese normal subjects $* p<.05 . * * p<.01 . * * * p<.001$ 
Table 2 Brain regions with significant correlations between regional gray matter volume (rGMV) and the CM, DA, OR scores, respectively

\begin{tabular}{|c|c|c|c|c|c|c|c|}
\hline \multirow[t]{2}{*}{ Region } & \multirow[t]{2}{*}{$\mathrm{BA}$} & \multirow[t]{2}{*}{ Side } & \multicolumn{3}{|c|}{ MNI coordinate } & \multirow[t]{2}{*}{ Peak $t$ value } & \multirow[t]{2}{*}{ Cluster size $\left(\mathrm{mm}^{3}\right)$} \\
\hline & & & $x$ & $y$ & $z$ & & \\
\hline \multicolumn{8}{|c|}{ Positive correlation between rGMV and the CM score } \\
\hline $\mathrm{ACC}$ & & $\mathrm{R}$ & 14 & 25 & 24 & 3.78 & $131^{\mathrm{b}}$ \\
\hline \multirow[t]{2}{*}{$\mathrm{MCC}$} & & \multirow[t]{2}{*}{$\mathrm{R}$} & 10 & 13 & 32 & 3.26 & $87^{\mathrm{b}}$ \\
\hline & & & 10 & -5 & 38 & 3.74 & $93^{\mathrm{b}}$ \\
\hline Insula & & $\mathrm{R}$ & 46 & -3 & 5 & 3.23 & $54^{\mathrm{b}}$ \\
\hline AG & 39 & $\mathrm{~L}$ & -44 & -62 & 39 & 3.46 & $270^{b}$ \\
\hline \multirow[t]{3}{*}{ STG } & 42 & $\mathrm{~L}$ & -58 & -47 & 21 & 3.09 & $105^{b}$ \\
\hline & & & -48 & 0 & 0 & 3.32 & \multirow[t]{2}{*}{$143^{b}$} \\
\hline & 38 & & -52 & 0 & -4 & 3.29 & \\
\hline \multicolumn{8}{|c|}{ Positive correlation between rGMV and the DA score } \\
\hline $\mathrm{ACC}$ & 32 & $\mathrm{R}$ & 2 & 39 & 26 & 3.78 & \multirow[t]{2}{*}{$180^{\mathrm{b}}$} \\
\hline & & & 0 & 43 & 15 & 3.37 & \\
\hline \multirow[t]{2}{*}{ IFG (triangular part) } & 48 & $\mathrm{~L}$ & -38 & 33 & 21 & 3.32 & \multirow[t]{2}{*}{$228^{b}$} \\
\hline & 48 & & -40 & 28 & 15 & 3.16 & \\
\hline \multirow[t]{5}{*}{ SMA } & \multirow{3}{*}{8} & \multirow[t]{5}{*}{$\mathrm{L}$} & 0 & 22 & 44 & 3.14 & \multirow[t]{3}{*}{$151^{\mathrm{b}}$} \\
\hline & & & -8 & 22 & 50 & 3.10 & \\
\hline & & & 0 & 18 & 51 & 3.09 & \\
\hline & 6 & & -10 & 3 & 48 & 3.88 & $308^{b}$ \\
\hline & & & 0 & -3 & 53 & 3.38 & \\
\hline \multirow[t]{3}{*}{$\mathrm{ACC}$} & 32 & $\mathrm{~L}$ & -10 & 27 & 32 & 3.55 & \multirow[t]{3}{*}{$1453^{a}$} \\
\hline & 32 & $\mathrm{R}$ & 2 & 39 & 26 & 3.78 & \\
\hline & & $\mathrm{R}$ & 0 & 45 & 14 & 3.45 & \\
\hline \multicolumn{8}{|c|}{ Negative correlation between rGMV and the DA score } \\
\hline IFG (triangular part) & 47 & $\mathrm{R}$ & 49 & 32 & -3 & 3.76 & $218^{\mathrm{b}}$ \\
\hline IFG (orbital part) & 47 & $\mathrm{R}$ & 49 & 30 & -6 & 4.05 & $344^{\mathrm{b}}$ \\
\hline Insula & 48 & $\mathrm{~L}$ & -28 & 24 & 11 & 3.78 & $305^{b}$ \\
\hline \multicolumn{8}{|c|}{ Positive correlation between rGMV and the OR score } \\
\hline IFG (triangular part) & 47 & $\mathrm{~L}$ & -45 & 31 & -3 & 4.02 & $659^{\mathrm{b}}$ \\
\hline
\end{tabular}

Note $\mathrm{ACC}=$ anterior cingulate cortex; $\mathrm{MCC}=$ midcingulate cortex; $\mathrm{AG}=$ angular gyrus; $\mathrm{STG}=$ superior temporal gyrus; $\mathrm{IFG}$ (triangular part) $=$ triangular part of inferior frontal gyrus; SMA = supplementary motor area; IFG (orbital part) = orbital part of inferior frontal gyrus; BA = Brodmann area; $\mathrm{L}=$ left; $\mathrm{R}=$ right; $\mathrm{MNI}=$ Montreal Neurological Institute

${ }^{\mathrm{a}} p<.05$ whole brain nonstationary corrected for multiple comparisons at the cluster level. ${ }^{\mathrm{b}} p<.05$ small volume correction (SVC) for multiple comparisons with a strong priori hypothesis

$(r=.468, p<.001)$, and SDS scores $(r=.442, p<.001)$, respectively, but also a positive relationship between the DA score and the rGMV of ACC $(r=.292, p<.001)$ after controlling for gender, age, and global GMV. It suggested that DA might act as a mediator in the relationships among these variables. Then, we tested whether DA mediated the correlation of the rGMV of ACC and individual self-reported anxiety or depression or not by using the scripts written by Andrew F. Hayes in SPSS 16.0 (http://www.afhayes.com/spss-sas-andmplus-macros-and-code.html; Preacher \& Hayes, 2004, 2008). In mediation analysis, we chose the GMV of ACC as the independent variable (IV), SAS or SDS scores as the dependent variable (DV), respectively, and DA score as the proposed mediator. We also included gender, age, and wholebrain GMV as the control variables for all mediation analyses.
As expected, mediation analyses revealed that the rGMV of the ACC had a significant indirect effect on both SAS and SDS, respectively, with DA as a mediator. The effect of the ACC on SAS decreased and did not reach significance $(\beta=$ $0.11, n s)$ after including DA as a mediator in the model. In contrast, the direct relationship namely the total effect was significant $(\beta=0.31, p<.05)$. A bootstrap simulation $(n=$ $10,000)$ further confirmed that this reduction was statistically significant (95\% CI [0.11, 0.33], $p<.05)$ (see Fig. 2a). Similarly, the effect of the ACC on SDS also decreased and did not achieve significance $(\beta=0.07, n s)$, after setting DA as a mediator in the model. However, the direct relationship, namely the total effect, was significant $(\beta=0.26, p<.05)$. A bootstrap simulation $(n=10,000)$ further confirmed that this reduction was statistically significant $(95 \%$ CI $[0.09$, 


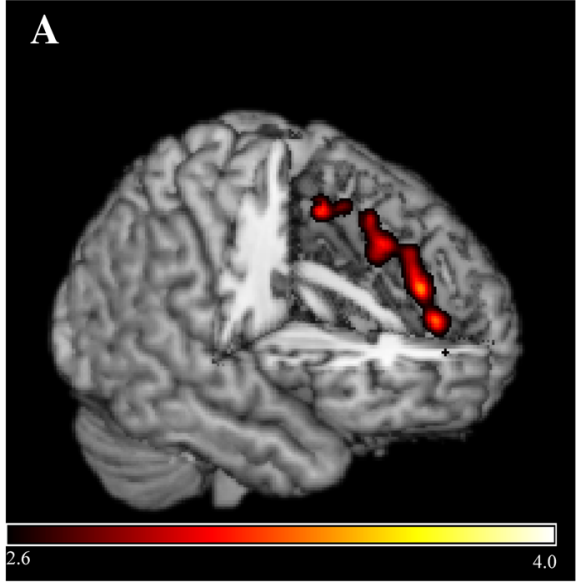

Fig. 1 Brain regions show a correlation with the doubts about actions (DA) scores. a The rGMV of the anterior cingulate cortex (ACC) is positively correlated with DA. The left figure was displayed by using the MRIcron software (http://www.mccauslandcenter.sc.
B
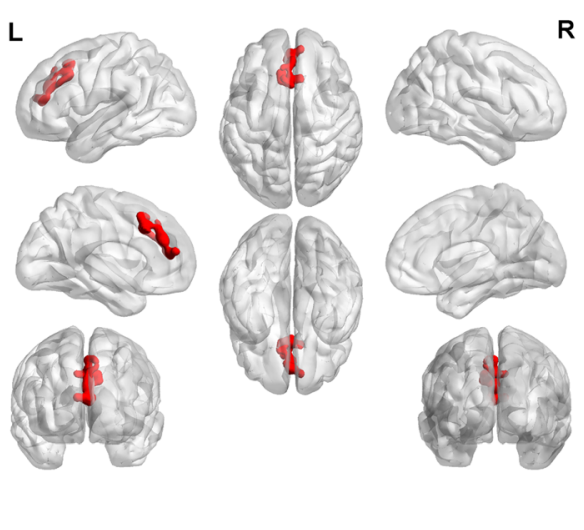

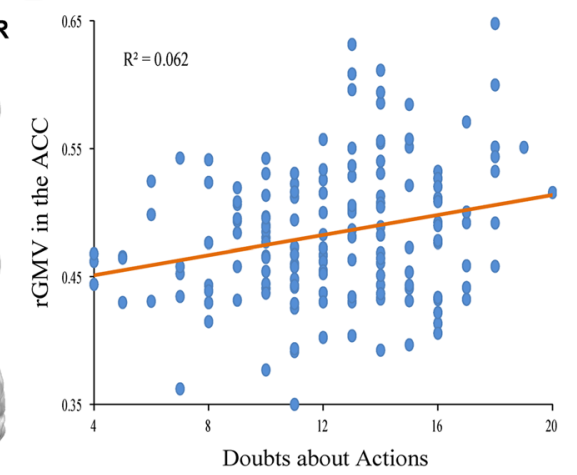

edu/mricro/mricron/index.html), and the right figure was displayed using the BrainNet Viewer software (Xia, Wang, \& He, 2013). b Scatter plots depict a correlation between the rGMV in the ACC and individual differences in DA $(r=.249, p=.001)$
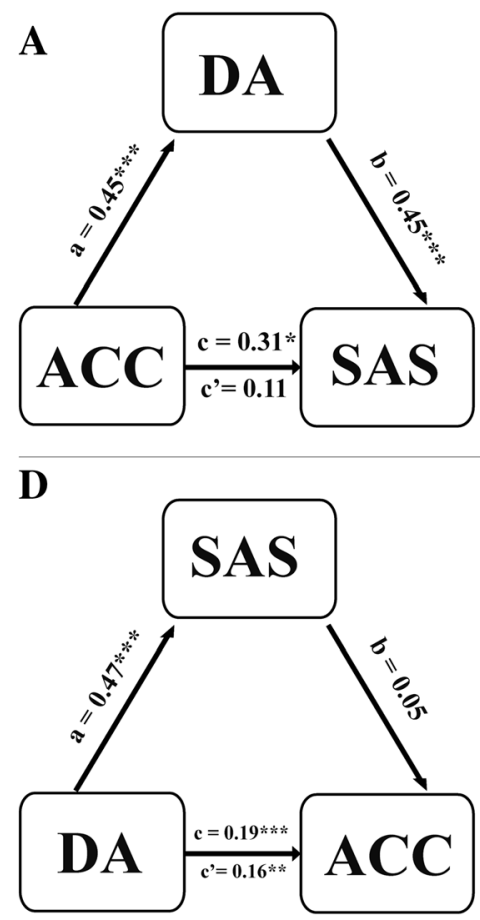

Fig. 2 The doubts about actions (DA) scores mediate the association between the brain structure, the anterior cingulate cortex (ACC), and SAS, SDS scores $(\mathbf{a}, \mathbf{b}, \mathbf{c})$, and the SAS, SDS, NA score as mediator, respectively, in the association between DA score and the gray matter volume (GMV) of ACC for addition analyses $(\mathbf{d}, \mathbf{e}, \mathbf{f})$. a Path diagram (including coefficients) of the mediation analysis demonstrating that the rGMV in the ACC affected individuals' SAS through DA, and the ab effect is 0.20 (without gender, age and global GMV as covariates, the effect of ab paths is $0.11, p=.0038$ ). b Path diagram (including coefficients) of the mediation analysis demonstrating that the rGMV in the ACC affected individuals' SDS via DA, and the ab effect is 0.19 (without gender, age and global GMV as covariates, the effect of ab paths is $0.11, p=.0043$ ). $\mathbf{c}$ Path diagram (including coefficients) of the mediation analysis demonstrating that the rGMV in the ACC affected individuals' negative affect via DA, and the ab effect is 0.21 (without

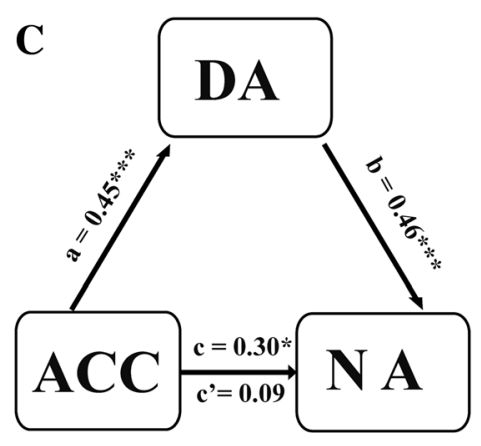

F

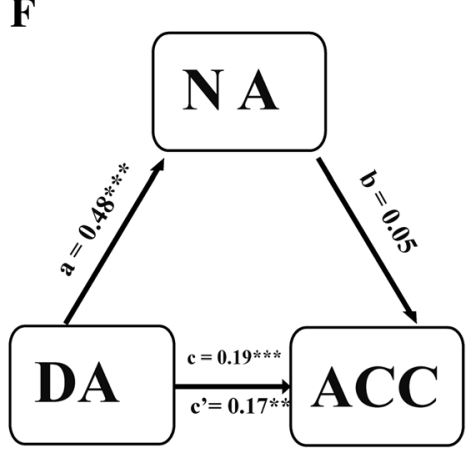

gender, age and global GMV as covariates, the effect of ab paths is $0.12, p$ $=.0036)$. $(\mathbf{d}, \mathbf{e}, \mathbf{f})$ Path diagram (including coefficients) of the mediation analysis that DA as the IV, the GMV of ACC as the DV and SAS, SDS or NA as the proposed mediator respectively, and none of the $b$ paths in the three models were significant, but the c' paths were still remain significant. The ab effect is 0.02 (without gender, age and global GMV as covariates, the effect of ab paths is $0.01, p=0.86$ ) in $\mathbf{~}$. The ab effect is 0.02 (without gender, age, and global GMV as covariates, the effect of ab paths is $0.0002, p=0.9948$ ) in e. The ab effect is 0.02 (without gender, age, and global GMV as covariates, the effect of ab paths is $0.02, p=0.65$ ) in $\mathbf{f}$. Note SAS = scores of the Self-Rating Anxiety Scale; SDS = scores of the Self-Rating Depression Scale; NA = the scores of the negative affect, combining the scores of the Self-Rating Anxiety Scale with the scores of the Self-Rating Depression Scale $* p<.05$. $* * p<.01 . * * * p<.001$ 
0.33], $p<.05$; see Fig. 2b). In summary, the two mediation model suggested that DA played a mediating role in the relationship between the GMV of ACC and negative emotion.

Depression and anxiety are two common factors of negative affect, and a combining score between depressive and anxious score seems more convincing. Thus, we averaged these two scores as the negative affect score in this study. For mediation analysis, we chose the GMV of ACC as the $\mathrm{IV}$, the negative affect score as the DV and DA score as the proposed mediator respectively. In addition, we controlled for gender, age, and whole-brain GMV in this mediation analysis. Similarly, the effect of the ACC on the negative affect also decreased and did not reach significant $(\beta=0.09, n s)$ after setting DA as a mediator. However, the direct relationship namely the total effect was significant $(\beta=0.30, p<.05)$. A bootstrap simulation $(n=10,000)$ further confirmed this reduction was statistically significant (95\% CI [0.10, 0.35], $p<$ .05; see Fig. 2c).

To verify that DA was playing a central role in mediating the relationship between the GMV of ACC and the individual differences of negative emotion (SAS, SDS, NA), we also conducted additional analyses as follows. We set DA as the IV, the GMV of ACC as the DV, and SAS, SDS, or NA as the proposed mediator, respectively. We found none of the $b$ paths in the three models were significant, but the c' paths were still remain significant. With SAS as a mediator in the model, mediation analyses revealed that the effect of the DA on ACC was still significant ( $\beta=0.16, p=.0039$ ), and the direct relationship, namely the total effect, was significant $(\beta=0.19$, $p=.0002)$, but the $\mathrm{b}$ paths were not significant $(\beta=0.05, p=$ .3531 ), and the ab effect is 0.02 (without gender, age, and global GMV as covariates, the effect of ab paths is $0.01 ; p=$ .86). A bootstrap simulation ( $n=10,000)$ further confirmed this reduction was statistically significant $(95 \%$ CI $[-0.04$, $0.10], p<.05$; see Fig. 2d). After including SDS as a mediator in the model, mediation analyses revealed that the effect of the DA on ACC was still significant ( $\beta=0.17, p=.002$ ), and the direct relationship, namely the total effect, was significant $(\beta$ $=0.19, p=.0002)$, but the $\mathrm{b}$ paths were not significant $(\beta=$ $0.03, p=.5379$ ), and the ab effect is 0.02 ) without gender, age, and global GMV as covariates, the effect of ab paths is 0.0002 , $p=.9948)$. A bootstrap simulation $(n=10,000)$ further confirmed this reduction was statistically significant (95\% CI [$0.05,0.08], p<.05$; see Fig. 2e). Similarly, with NA as a mediator in the model, mediation analyses revealed that the effect of the DA on ACC was still significant $(\beta=0.17, p=$ .0036), and the direct relationship, namely the total effect, was significant $(\beta=0.19, p=.0002)$, but the $\mathrm{b}$ paths were not significant $(\beta=0.05, p=.4185)$, and the ab effect is 0.02 (without gender, age and global GMV as covariates, the effect of ab paths is $0.02, p=.65)$. A bootstrap simulation $(n=$ $10,000)$ further confirmed this reduction was statistically significant $(95 \% \mathrm{CI}=[-0.05,0.10], p<.05$; see Fig. $2 \mathrm{f})$. These results might more highly suggest that indeed DA is the critical variable in mediating the relationship between the GMV of ACC and the individual differences of negative emotion.

\section{Discussion}

In this study, we aimed at exploring the relationship among individual differences in perfectionism, brain structure, and negative emotion in a large, nonclinical sample of Chinese undergraduate students. As a result, both CM and DA, the two subdimensions of perfectionism, were positively correlated with individual difference in self-reported anxiety and depression as well as the GMV in the ACC, a crucial brain region supporting cognitive control and emotional regulation. Furthermore, the score of DA acted as a mediator in the relationship between the GMV of ACC and self-rating anxious, depressive emotion. As far as we know, our research might be the first to reveal the brain structural correlates of individual difference in perfectionism. Taken together, these results suggested perfectionism might play a significant role in the generation of negative affect.

\section{Relationship between perfectionism and negative emotion}

According to the behavioral results shown previously, the subdimensions of perfectionism, CM, DA, and OR were related to anxious and depressive emotion, while PS correlated only with anxiety, in our large, Chinese, nonclinical sample. The results were in line with previous findings (Enns et al., 2002; Frost et al., 1993; Frost, et al., 1990; Harris et al., 2008; Saboonchi \& Lundh, 1997; Wheeler et al., 2011; Zi \& Zhou, 2007). A factor analysis reported that $C M$ and DA could be clustered together to compose the main negative aspect of perfectionism, maladaptive evaluation concerns, and the central feature was evaluative concerns (Frost et al., 1993). Previous studies also found that CM and DA could be labeled as one factor with the characteristic of concerns, fear, and doubt (Purdon, Antony, \& Swinson, 1999; Stöber, 1998). Therefore, individuals with a high level of the CM, DA, and PS might fear errors, imperfect performance, and failure. Then, it would make them fail to meet their own standards or others' expectations, and lose others' respect. As a consequence, these individuals would have both intrapersonal and interpersonal problems, such as pressure, endless attempts to be perfect, and no time for fun and relaxation. Eventually, these experiences would elicit and maintain negative affects, such as anxiety and depression, and other health risks, including chronic fatigue and burnout (Arpin-Cribbie \& Cribbie, 2007; Shafran, Cooper, \& Fairburn, 2002; Shafran \& Mansell, 2001; Wirtz et al., 2007). Therefore, it is people who are more maladaptively perfectionistic that are more vulnerable to negative emotion. 
Our results also pointed out that OR score was negatively correlated with SAS and SDS scores. The dimension of OR was generally viewed as a kind of conscientious, normal, adaptive, and positive feature in the achievement striving factor of perfectionism because this trait could help individuals reduce the possibility of erring, assure the quality of performance and reach their own excessive criterions. At last, it would help lower undesirable emotions, such as anxiety or depression (DiBartolo \& Rendón, 2012).

\section{Relationship between brain structure variation and perfectionism}

We found that the CM and DA scores, which reflected the level of perfectionism, were related to brain regions mainly located in the right ACC. These results might suggest that ACC might be the neurological correlate of perfectionism, particularly maladaptive evaluative concerns (Bieling et al., 2004; Frost et al., 1993). A prior electroencephalogram study reported that DA and $\mathrm{CM}$ might be the significant predictors for the ACC activity in the standard Eriksen flankers task, because the DA subscale, linked to an "obsessional-like" thinking, reflects the extent to which people doubt their ability to accomplish tasks. Thus, individuals might show no confidence in their own performance and try to reach optimal results. With higher scores in the CM subscale, individuals will be more likely to react negatively to mistakes, present a tendency to interpret mistakes as equivalent to failure, and believe that they would lose others' respect due to failure (Schrijvers, De Bruijn, Destoop, Hulstijn, \& Sabbe, 2010). Given that the shared psychologically central feature in CM and DA (Bieling et al., 2004; Frost et al., 1993; Stöber, 1998), the relationship between the GMV of ACC with both CM and DA would be quite comprehensible. A higher CM score reflects more failure fear that might arouse individuals' negative affect. Then, they would show more tendencies to employ cognitive control to avoid action. As a representation of avoidance, DA reflected individuals' worries about the denial or rejection from others. Taken together, high association of ACC and two dimensions of perfectionism indicated individuals with high maladaptive perfectionism scores hesitated to take action because of fear of failure (Shafran et al., 2002).

More specifically, the clusters in our VBM results were comprised of a part of both AACC and VACC as the boundaries defined previously in a meta-analysis (Rotge et al., 2014). Evidence demonstrated that the dACC division mainly supported cognitive activities like cognitive control, error detection and conflict processing, while the vACC connected to the insula and orbitofrontal cortex primarily engaged in emotional processes such as affect state experience and regulation (Bush et al., 2000). However, dACC might involve in processing of individual emotion as well (Etkin, Egner, \& Kalisch, 2011). Previously, in a two-choice prediction task and at low error rates, individuals with high trait anxiety showed increased activation in ACC, mainly the dACC, and medial PFC. These regions also had a positive correlation with anxiety score (Paulus et al., 2004). During a virtual ball-tossing game, the $\mathrm{dACC}$ was more active in exclusion condition than in inclusion one and correlated positively with individuals' self-reported distress (Eisenberger, Lieberman, \& Williams, 2003). In this study, individuals with higher CM and DA scores might be concerned and have doubt about denial and social exclusion from others. Then, all these could make the ACC act analogously in the social rejection experiment along with negative moods such as anxiety and depression. Hence, it would be reasonable to speculate that the relationship between higher CM and DA scores and larger GMV in the ACC could be from the result of a use-dependent brain volume alteration (Giuliani, Drabant, \& Gross, 2011; May, 2011; Shackman et al., 2011).

In addition to the association with the $\mathrm{ACC}$, the $\mathrm{CM}$ and DA scores were correlated with multiple distributed brain regions, and these regions act a significant role in some cognitive and emotional processes. Overall, increased rGMV in the MCC, insula, STG, and AG were also observed in participants with higher CM scores. And the higher DA scores both correlated with the larger GMV in the left triangular part of the IFG and SMA, and with the smaller GMV in the right triangular and orbital parts of the IFG and insula. OR was also positively correlated with the rGMV in the left triangular part of the IFG. Previous research has demonstrated the important engagement of all these brain regions in multiple cognitive and emotional processes. For instance, the insula has been known to be involved in somatic and emotional awareness (Giuliani, Drabant, Bhatnagar, \& Gross, 2011), and the MCC, namely dACC (Stevens et al., 2011), has a strong association with cognitive control, action inhibition, punishment avoidance (Kohn et al., 2014), and negative emotion appraisal and expression (Etkin et al., 2011). But generally, all these distributed brain regions are involved in the processing of emotion (Giuliani, Drabant, Bhatnagar, \& Gross, 2011; Giuliani, Drabant, \& Gross, 2011; Kohn et al., 2014), implicating the latent neural substrates of emotion dysregulation in the maladaptive perfectionism individuals.

\section{Relationship among brain structure variation, perfectionism, and negative emotion}

Further mediation analysis revealed that the score of the DA acted a mediational mechanism in the correlation between the $\mathrm{ACC}$ and negative affect, including self-rating anxious and depressive symptoms. As depicted above, that the DA score was associated with the rGMV of the ACC might suggest that individuals with greater $\mathrm{ACC}$ would be more inclined to show concern about their deed and evaluate what they did so extremely critically that they would be more sensitive to 
negative emotion. Thus, the relationship between the rGMV of the ACC and individual difference in anxiety and depression could be induced by the indirect effect of DA. Inferred from the role of the ACC in the processing of cognitive control and negative affect (Shackman et al., 2011) and the main characteristic of DA, excessively severe self-evaluation combined with evaluative concerns (Frost et al., 1990), the positive relationship between the rGMV of the ACC and the score of DA seems to be reasonable. Notwithstanding that the mechanisms underlying the positive correlation between the larger GMV in the ACC and the higher level of anxiety and depression in this study remain unclear, prior findings of structural differences in adolescent mood and anxiety disorders might provide clues. For example, a recent study in adolescent anxiety reported that there was a larger dACC GMV in anxious adolescents modulated by the brain-derived neurotropic factor $\mathrm{Val}^{66} \mathrm{Met}$ Polymorphism (Mueller et al., 2013). However, there was disagreement in the relationship between the GMV in the ACC and the level of anxiety and depression. For example, a study reported that the ACC volume was positively related to cognitive reappraisal but not negative affect (Giuliani, Drabant, \& Gross, 2011). Regardless of the inconclusive and controversial relationship between brain structure size and function intensity (Kanai, Dong, Bahrami, \& Rees, 2011; Kanai \& Rees, 2011; Takeuchi et al., 2013), there might be some possible inference for this result. First of all, two ACC subdivisions are included in our results, vACC and dACC, which are involved in the integration of cognitive and emotional information, especially cognitive control and negative affect, error-related activity as well as self-reported distress rather than the emotional regulation solely (Bush et al., 2000; Mohanty et al., 2007; Rotge et al., 2014). More important, there are also differences in the analytical method and materials. Indeed, we got our results from the correlation between perfectionism and whole-brain GMV in a larger sample instead of the ROIs drawn manually in previous work (Giuliani, Drabant, \& Gross, 2011). There might be a usedependent volume alteration in GMV of ACC in our sample due to the interaction among perfectionism, the processing of cognitive control and personal distress (Giuliani, Drabant, \& Gross, 2011; May, 2011; Shackman et al., 2011). After all, our results substantiated that perfectionism could serve as an underlying mechanism explaining the association between the rGMV in the ACC and individual differences in anxious and depressive affect.

\section{Limitations of current study}

Several limitations to this study pertain to the methods for evaluation, the interpretation of current results, as well as the usage of MRI data. The first set of limitations concerns the assessment of perfectionism and self-reported negative emotion. Using multiple methods for evaluation might be better to confirm the results about neural mechanism of perfectionism (Bieling et al., 2004; Chang et al., 2008; Shafran \& Mansell, 2001). For example, HMPS, including scales of self-oriented perfectionism, socially prescribed perfectionism, and otheroriented perfectionism, mainly focused on the interpersonal factor of perfectionism; it focused less on personal characteristics and described features of perfectionism in more detail (Zi \& Zhou, 2007; Zi et al., 2010). Besides, we relied entirely on self-reported measures, which could be biased by depressed or anxious mood in the respondents' temporal status, and it would be better to incorporate more objective measures in future research (Enns et al., 2002). Another possible limitation was the interpretation of current results. Caution should be used when interpreting the present results because our cross-sectional design does not allow us to draw conclusions about the directions of causality among brain structure variation, perfectionism, and anxiety and depression. It is particularly necessary to investigate this relationship in longitudinal research. Because no difference of perfectionism between gender was observed in our study, in accordance with previous findings (Besharat et al., 2014), we did not take the gender difference factor into account in this research. All data came from a large, nonclinical sample of Chinese undergraduate students, making these results not easily generalized to other populations. Therefore, it would be helpful to explore relationships in other general samples, such as clinical patients. A final set of limitations concerns the deficient usage of MRI data and analysis methods. In this study, we only used the VBM analysis to investigate the relationship among brain GMV changes, perfectionism, and negative emotion, which might obscure crucial results and influence on our interpretation of the current results and further understanding (Giuliani, Drabant, Bhatnagar, \& Gross, 2011). Hence, based on existing work, an investigation from structural or functional networks of perfectionism should be taken into consideration. All limitations mentioned above should be addressed in future works-or instance, more comprehensive measures conducting longitudinal research and more MRI data analyses.

\section{Conclusions}

In conclusion, this preliminary study employing the VBM approach to explore the association among perfectionism, brain structure, and negative emotion offers considerable promise. First, we replicated the result of the significant correlation between perfectionism and negative emotion, which demonstrated that the association between maladaptive perfectionism and negative mood did exist in a large Chinese undergraduate population. Besides, based on the employment of the VBM approach, perfectionism showed an association with some brain regions in the GMV, specifically the ACC, 
revealing a potential neural mechanism for emotional dysregulation in individuals with maladaptive perfectionism. Finally, a follow-up mediation analysis revealed a mediational mechanism of the DA in the relation between the GMV of ACC and self-rating anxious, depressive affect. In sum, these findings not only provided evidence for the relationship between perfectionism and negative affect but also revealed the association among brain structure variation, perfectionism, and negative affect. Our finding indicated the potential role of perfectionism in the processing of negative emotion.

Acknowledgments This research was supported by the National Natural Science Foundation of China (31271087; 31470981; 31571137; 31500885), National Outstanding Young People Plan, the Program for the Top Young Talents by Chongqing, the Fundamental Research Funds for the Central Universities (SWU1509383), Natural Science Foundation of Chongqing (cstc2015jcyjA10106), General Financial Grant from the China Postdoctoral Science Foundation (2015 M572423). The authors declare no competing interests.

\section{References}

Aldea, M. A., \& Rice, K. G. (2006). The role of emotional dysregulation in perfectionism and psychological distress. Journal of Counseling Psychology, 53(4), 498.

Arpin-Cribbie, C. A., \& Cribbie, R. A. (2007). Psychological correlates of fatigue: Examining depression, perfectionism, and automatic negative thoughts. Personality and Individual Differences, 43(6), 1310 1320.

Ashburner, J. (2007). A fast diffeomorphic image registration algorithm. NeuroImage, 38(1), 95-113. doi:10.1016/j.neuroimage.2007.07.007

Bachner-Melman, R., Lerer, E., Zohar, A. H., Kremer, I., Elizur, Y., Nemanov, L., ... Ebstein, R. P. (2007). Anorexia nervosa, perfectionism, and dopamine D4 receptor (DRD4). American Journal of Medical Genetics Part B: Neuropsychiatric Genetics, 144B(6), 748756. doi:10.1002/ajmg.b.30505

Balazs, J., Miklósi, M., Kereszteny, A., Hoven, C. W., Carli, V., Wasserman, C., ... Cotter, P. (2013). Adolescent subthreshold depression and anxiety: Psychopathology, functional impairment and increased suicide risk. Journal of Child Psychology and Psychiatry, 54(6), 670-677.

Besharat, M. A., Issazadegan, A., Etemadinia, M., Golssanamlou, S., \& Abdolmanafi, A. (2014). Risk factors associated with depressive symptoms among undergraduate students. Asian Journal of Psychiatry, 10, 21-26. doi:10.1016/j.ajp.2014.02.002

Bieling, P. J., Summerfeldt, L. J., Israeli, A. L., \& Antony, M. M. (2004). Perfectionism as an explanatory construct in comorbidity of axis I disorders. Journal of Psychopathology and Behavioral Assessment, 26(3), 193-201.

Biggs, J. T., Wylie, L. T., \& Ziegler, V. E. (1978). Validity of the zung self-rating depression scale. The British Journal of Psychiatry, 132(4), 381-385.

Bishop, S. J. (2009). Trait anxiety and impoverished prefrontal control of attention. Nature Neuroscience, 12(1), 92-98. doi:10.1038/nn.2242

Blankstein, K. R., \& Lumley, C. H. (2008). Multidimensional perfectionism and ruminative brooding in current dysphoria, anxiety, worry, and anger. Journal of Rational-Emotive \& Cognitive-Behavior Therapy, 26(3), 168-193.

Blatt, S. J., Quinlan, D. M., Pilkonis, P. A., \& Shea, M. T. (1995). Impact of perfectionism and need for approval on the brief treatment of depression: The national institute of mental health treatment of depression collaborative research program revisited. Journal of Consulting and Clinical Psychology, 63(1), 125.

Blatt, S. J., Zuroff, D. C., Bondi, C. M., Sanislow, C. A., III, \& Pilkonis, P. A. (1998). When and how perfectionism impedes the brief treatment of depression: Further analyses of the national institute of mental health treatment of depression collaborative research program. Journal of Consulting and Clinical Psychology, 66(2), 423.

Buhle, J. T., Silvers, J. A., Wager, T. D., Lopez, R., Onyemekwu, C., Kober, H., ... Ochsner, K. N. (2014). Cognitive reappraisal of emotion: A meta-analysis of human neuroimaging studies. Cerebral Cortex, 24(11), 2981-2990. doi:10.1093/cercor/bht154

Burns, D. D. (1980). The perfectionist's script for self-defeat. Psychology Today, 14(6), 34-52.

Bush, G., Luu, P., \& Posner, M. I. (2000). Cognitive and emotional influences in anterior cingulate cortex. Trends in Cognitive Sciences, 4(6), 215-222.

Chang, E. C., Ivezaj, V., Downey, C. A., Kashima, Y., \& Morady, A. R. (2008). Complexities of measuring perfectionism: Three popular perfectionism measures and their relations with eating disturbances and health behaviors in a female college student sample. Eating Behaviors, 9(1), 102-110. doi:10.1016/j.eatbeh.2007.06.003

Cheng, P., Dolsen, M., Girz, L., Rudowski, M., Chang, E., \& Deldin, P. (2015). Understanding perfectionism and depression in an adult clinical population: Is outcome expectancy relevant to psychological functioning? Personality and Individual Differences, 75, 64-67.

Cooney, R. E., Joormann, J., Eugene, F., Dennis, E. L., \& Gotlib, I. H. (2010). Neural correlates of rumination in depression. Cognitive, Affective, \& Behavioral Neuroscience, 10(4), 470-478. doi:10.3758/CABN.10.4.470

Davies, B., Burrows, G., \& Poynton, C. (1975). A comparative study of four depression rating scales. Australian and New Zealand Journal of Psychiatry, 9(1), 21-24.

Di Schiena, R., Luminet, O., Philippot, P., \& Douilliez, C. (2012). Adaptive and maladaptive perfectionism in depression: Preliminary evidence on the role of adaptive and maladaptive rumination. Personality and Individual Differences, 53(6), 774-778.

DiBartolo, P. M., \& Rendon, M. J. (2012). A critical examination of the construct of perfectionism and its relationship to mental health in Asian and African Americans using a cross-cultural framework. Clinical Psychology Review, 32(3), 139-152. doi:10.1016/j. cpr.2011.09.007

Dobson, K. S. (1985). An analysis of anxiety and depression scales. Journal of Personality Assessment, 49(5), 522-527.

Ducharme, S., Dougherty, D. D., \& Drevets, W. C. (2016). Neuroimaging and neurocircuitry of obsessive-compulsive disorder and major depressive disorder. In J. A. Camprodon, S. L. Rauch, B. D. Greenberg, \& D. D. Dougherty (Eds.), Psychiatric neurotherapeutics (pp. 51-77). New York: Springer.

Eden, A. S., Schreiber, J., Anwander, A., Keuper, K., Laeger, I., Zwanzger, P., ... Dobel, C. (2015). Emotion regulation and trait anxiety are predicted by the microstructure of fibers between amygdala and prefrontal cortex. Journal of Neuroscience, 35(15), 6020 6027. doi:10.1523/JNEUROSCI.3659-14.2015

Egan, S. J., Wade, T. D., \& Shafran, R. (2011). Perfectionism as a transdiagnostic process: A clinical review. Clinical Psychology Review, 31(2), 203-212. doi:10.1016/j.cpr.2010.04.009

Eisenberger, N. I., Lieberman, M. D., \& Williams, K. D. (2003). Does rejection hurt? An FMRI study of social exclusion. Science, 302(5643), 290292. doi:10.1126/science. 1089134

Enns, M. W., Cox, B. J., \& Clara, I. (2002). Adaptive and maladaptive perfectionism: Developmental origins and association with depression proneness. Personality and Individual Differences, 33(6), 921935.

Etkin, A., Egner, T., \& Kalisch, R. (2011). Emotional processing in anterior cingulate and medial prefrontal cortex. Trends in Cognitive Science, 15(2), 85-93. doi:10.1016/j.tics.2010.11.004 
Fitzgerald, K. D., Welsh, R. C., Gehring, W. J., Abelson, J. L., Himle, J. A., Liberzon, I., \& Taylor, S. F. (2005). Error-related hyperactivity of the anterior cingulate cortex in obsessive-compulsive disorder. Biological Psychiatry, 57(3), 287-294. doi:10.1016/j.biopsych.2004.10.038

Flett, G. L., Madorsky, D., Hewitt, P. L., \& Heisel, M. J. (2002). Perfectionism cognitions, rumination, and psychological distress. Journal of Rational-Emotive \& Cognitive-Behavior Therapy, 20(1), 33-47.

Frost, R. O., Heimberg, R. G., Holt, C. S., Mattia, J. I., \& Neubauer, A. L. (1993). A comparison of two measures of perfectionism. Personality and Individual Differences, 14(1), 119-126.

Frost, R. O., Marten, P., Lahart, C., \& Rosenblate, R. (1990). The dimensions of perfectionism. Cognitive Therapy and Research, 14(5), 449-468.

Garner, D. M., Olmstead, M. P., \& Polivy, J. (1983). Development and validation of a multidimensional eating disorder inventory for anorexia nervosa and bulimia. International Journal of Eating Disorders, 2(2), 15-34.

Giuliani, N. R., Drabant, E. M., Bhatnagar, R., \& Gross, J. J. (2011). Emotion regulation and brain plasticity: Expressive suppression use predicts anterior insula volume. NeuroImage, 58(1), 10-15. doi:10.1016/j.neuroimage.2011.06.028

Giuliani, N. R., Drabant, E. M., \& Gross, J. J. (2011). Anterior cingulate cortex volume and emotion regulation: Is bigger better? Biological Psychology, 86(3), 379-382. doi:10.1016/j.biopsycho.2010.11.010

Graybiel, A. M., \& Rauch, S. L. (2000). Toward a neurobiology of obsessive-compulsive disorder. Neuron, 28(2), 343-347.

Harris, P. W., Pepper, C. M., \& Maack, D. J. (2008). The relationship between maladaptive perfectionism and depressive symptoms: The mediating role of rumination. Personality and Individual Differences, 44(1), 150-160.

Hayasaka, S., Phan, K. L., Liberzon, I., Worsley, K. J., \& Nichols, T. E. (2004). Nonstationary cluster-size inference with random field and permutation methods. NeuroImage, 22(2), 676-687. doi:10.1016/j. neuroimage.2004.01.041

Hewitt, P. L., Flett, G. L., Turnbull-Donovan, W., \& Mikail, S. F. (1991). The multidimensional perfectionism scale: Reliability, validity, and psychometric properties in psychiatric samples. Psychological Assessment: A Journal of Consulting and Clinical Psychology, 3(3), 464.

Julal, F. S. (2013). Use of student support services among university students: Associations with problem-focused coping, experience of personal difficulty and psychological distress. British Journal of Guidance and Counselling, 41(4), 414-425.

Kanai, R., Dong, M. Y., Bahrami, B., \& Rees, G. (2011). Distractibility in daily life is reflected in the structure and function of human parietal cortex. Journal of Neuroscience, 31(18), 6620-6626. doi:10.1523/JNEUROSCI.5864-10.2011

Kanai, R., \& Rees, G. (2011). The structural basis of inter-individual differences in human behaviour and cognition. Nature Reviews Neuroscience, 12(4), 231242. doi:10.1038/nrn3000

Kawamura, K. Y., Hunt, S. L., Frost, R. O., \& DiBartolo, P. M. (2001). Perfectionism, anxiety, and depression: Are the relationships independent? Cognitive Therapy and Research, 25(3), 291-301.

Kim, M. J., \& Whalen, P. J. (2009). The structural integrity of an amygdalaprefrontal pathway predicts trait anxiety. Journal of Neuroscience, 29(37), 11614-11618. doi:10.1523/JNEUROSCI.2335-09.2009

Kohn, N., Eickhoff, S. B., Scheller, M., Laird, A. R., Fox, P. T., \& Habel, U. (2014). Neural network of cognitive emotion regulation-An ALE meta-analysis and MACM analysis. NeuroImage, 87, 345355. doi:10.1016/j.neuroimage.2013.11.001

Lee, J. C., Prado, H. S., Diniz, J. B., Borcato, S., da Silva, C. B., Hounie, A. G.,...do Rosario, M. C. (2009). Perfectionism and sensory phenomena: Phenotypic components of obsessive-compulsive disorder. Comprehensive Psychiatry, 50(5), 431-436. doi:10.1016/j. comppsych.2008.11.007
Lewis, G. J., Kanai, R., Rees, G., \& Bates, T. C. (2014). Neural correlates of the 'good life': Eudaimonic well-being is associated with insular cortex volume. Social Cognitive and Affective Neuroscience, 9(5), 615-618. doi:10.1093/scan/nst032

Li, H., Li, W., Wei, D., Chen, Q., Jackson, T., Zhang, Q., \& Qiu, J. (2014). Examining brain structures associated with perceived stress in a large sample of young adults via voxel-based morphometry. NeuroImage, 92, 1-7. doi:10.1016/j.neuroimage.2014.01.044

Lindner, S. E., Fichter, M. M., \& Quadflieg, N. (2013). Central coherence in full recovery of anorexia nervosa. European Eating Disorders Review, 21(2), 115-120. doi:10.1002/erv.2213

Maldjian, J. A., Laurienti, P. J., Kraft, R. A., \& Burdette, J. H. (2003). An automated method for neuroanatomic and cytoarchitectonic atlasbased interrogation of fMRI data sets. NeuroImage, 19(3), 12331239.

Maldjian, J. A., Laurienti, P. J., \& Burdette, J. H. (2004). Precentral gyrus discrepancy in electronic versions of the Talairach atlas. NeuroImage, 21(1), 450-455.

May, A. (2011). Experience-dependent structural plasticity in the adult human brain. Trends in Cognitive Science, 15(10), 475-482. doi:10.1016/j.tics.2011.08.002

Meites, K., Lovallo, W., \& Pishkin, V. (1980). A comparison of four scales for anxiety, depression, and neuroticism. Journal of Clinical Psychology, 36(2), 427-432.

Mohanty, A., Engels, A. S., Herrington, J. D., Heller, W., Ho, M. H., Banich, M. T., ... Miller, G. A. (2007). Differential engagement of anterior cingulate cortex subdivisions for cognitive and emotional function. Psychophysiology, 44(3), 343-351. doi:10.1111/j.14698986.2007.00515.x

Morawetz, C., Bode, S., Baudewig, J., Kirilina, E., \& Heekeren, H. R. (2016). Changes in effective connectivity between dorsal and ventral prefrontal regions moderate emotion regulation. Cerebral Cortex, 26(5), 1923-1937. doi:10.1093/cercor/bhv005

Mueller, S. C., Aouidad, A., Gorodetsky, E., Goldman, D., Pine, D. S., \& Ernst, M. (2013). Gray matter volume in adolescent anxiety: An impact of the brain-derived neurotrophic factor Val(66)Met polymorphism? Journal of the American Academy of Child and Adolescent Psychiatry, 52(2), 184-195. doi:10.1016/j.jaac.2012.11.016

Mühlau, M., Gaser, C., Ilg, R., Conrad, B., Leibl, C., Cebulla, M. H., ... Wohlschläger, A. M. (2007). Gray matter decrease of the anterior cingulate cortex in anorexia nervosa. American Journal of Psychiatry, 164(12), 1850-1857.

O'Connor, R. C., \& Nock, M. K. (2014). The psychology of suicidal behaviour. The Lancet Psychiatry, 1(1), 73-85.

O'Connor, R. C., Rasmussen, S., \& Hawton, K. (2010). Predicting depression, anxiety and self-harm in adolescents: The role of perfectionism and acute life stress. Behavior Research and Therapy, 48(1), 52-59. doi:10.1016/j.brat.2009.09.008

Olatunji, B. O., Deacon, B. J., Abramowitz, J. S., \& Tolin, D. F. (2006). Dimensionality of somatic complaints: Factor structure and psychometric properties of the Self-Rating Anxiety Scale. Journal of Anxiety Disorders, 20(5), 543-561. doi:10.1016/j.janxdis.2005.08.002

Paulus, M. P., Feinstein, J. S., Simmons, A., \& Stein, M. B. (2004). Anterior cingulate activation in high trait anxious subjects is related to altered error processing during decision making. Biological Psychiatry, 55(12), 1179-1187. doi:10.1016/j.biopsych.2004.02.023

Pravettoni, G., Cropley, M., Leotta, S. N., \& Bagnara, S. (2007). The differential role of mental rumination among industrial and knowledge workers. Ergonomics, 50(11), 1931-1940.

Preacher, K. J., \& Hayes, A. F. (2004). SPSS and SAS procedures for estimating indirect effects in simple mediation models. Behavior Research Methods, Instruments, \& Computers, 36(4), 717-731.

Preacher, K. J., \& Hayes, A. F. (2008). Asymptotic and resampling strategies for assessing and comparing indirect effects in multiple mediator models. Behavior Research Methods, 40(3), 879-891. 
Purdon, C., Antony, M. M., \& Swinson, R. P. (1999). Psychometric properties of the frost multidimensional perfectionism scale in a clinical anxiety disorders sample. Journal of Clinical Psychology, 55(10), 1271-1286.

Qiao, L., Wei, D. T., Li, W. F., Chen, Q. L., Che, X. W., Li, B. B., ... Liu, Y. J. (2013). Rumination mediates the relationship between structural variations in ventrolateral prefrontal cortex and sensitivity to negative life events. Neuroscience, 255, 255-264. doi:10.1016/j. neuroscience.2013.09.053

Rhéaume, J., Freeston, M. H., Dugas, M. J., Letarte, H., \& Ladouceur, R. (1995). Perfectionism, responsibility and obsessive-compulsive symptoms. Behaviour Research and Therapy, 33(7), 785-794.

Ridgway, G. R., Omar, R., Ourselin, S., Hill, D. L., Warren, J. D., \& Fox, N. C. (2009). Issues with threshold masking in voxel-based morphometry of atrophied brains. NeuroImage, 44(1), 99-111. doi:10.1016/j.neuroimage.2008.08.045

Rotge, J. Y., Lemogne, C., Hinfray, S., Huguet, P., Grynszpan, O., Tartour, E., ... Fossati, P. (2014). A meta-analysis of the anterior cingulate contribution to social pain. Social Cognitive and Affective Neuroscience, 10(1), 19-27. doi:10.1093/scan/nsu110

Rothemund, Y., Buchwald, C., Georgiewa, P., Bohner, G., Bauknecht, H. C., Ballmaier, M.,...Klingebiel, R. (2011). Compulsivity predicts fronto striatal activation in severely anorectic individuals. Neuroscience, 197, 242-250. doi:10.1016/j.neuroscience.2011.09.016

Rudolph, S. G., Flett, G. L., \& Hewitt, P. L. (2007). Perfectionism and deficits in cognitive emotion regulation. Journal of RationalEmotive \& Cognitive-Behavior Therapy, 25(4), 343-357.

Saboonchi, F., \& Lundh, L. G. (1997). Perfectionism, self-consciousness and anxiety. Personality and Individual Differences, 22(6), 921-928.

Sassaroli, S., Lauro, L. J., Ruggiero, G. M., Mauri, M. C., Vinai, P., \& Frost, R. (2008). Perfectionism in depression, obsessive-compulsive disorder and eating disorders. Behaviour Research and Therapy, 46(6), 757-765. doi:10.1016/j.brat.2008.02.007

Schrijvers, D. L., De Bruijn, E. R., Destoop, M., Hulstijn, W., \& Sabbe, B. G. (2010). The impact of perfectionism and anxiety traits on action monitoring in major depressive disorder. Journal of Neural Transmission, 117(7), 869-880. doi:10.1007/s00702-010-0419-2

Sevlever, M., \& Rice, K. G. (2010). Perfectionism, depression, anxiety, and academic performance in premedical students. Canadian Medical Education Journal, 1(2), 96-104.

Shackman, A. J., Salomons, T. V., Slagter, H. A., Fox, A. S., Winter, J. J., \& Davidson, R. J. (2011). The integration of negative affect, pain and cognitive control in the cingulate cortex. Nature Reviews Neuroscience, 12(3), 154-167. doi:10.1038/nrn2994

Shafran, R., Cooper, Z., \& Fairburn, C. G. (2002). Clinical perfectionism: A cognitive-behavioural analysis. Behaviour Research and Therapy, 40(7), 773-791.

Shafran, R., \& Mansell, W. (2001). Perfectionism and psychopathology: A review of research and treatment. Clinical Psychology Review, 21(6), 879-906.

Shahid, A., Chung, S. A., Maresky, L., Danish, A., Bingeliene, A., Shen, J., \& Shapiro, C. M. (2016). The Toronto hospital alertness test scale: Relationship to daytime sleepiness, fatigue, and symptoms of depression and anxiety. Nature and Science of Sleep, 8, 41.

Stevens, F. L., Hurley, R. A., \& Taber, K. H. (2011). Anterior cingulate cortex: Unique role in cognition and emotion. The Journal of Neuropsychiatry and Clinical Neurosciences. doi:10.1176/jnp.23.2.jnp121

Stöber, J. (1998). The frost multidimensional perfectionism scale revisited: More perfect with four (instead of six) dimensions. Personality and Individual Differences, 24(4), 481-491.

Sylvester, C. M., Corbetta, M., Raichle, M. E., Rodebaugh, T. L., Schlaggar, B. L., Sheline, Y. I., ... Lenze, E. J. (2012). Functional network dysfunction in anxiety and anxiety disorders. Trends in Neuroscience, 35(9), 527-535. doi:10.1016/j.tins.2012.04.012
Takeuchi, H., Taki, Y., Nouchi, R., Hashizume, H., Sekiguchi, A., Kotozaki, Y., ... Kawashima, R. (2013). Anatomical correlates of self-handicapping tendency. Cortex, 49(4), 1148-1154. doi:10.1016/j.cortex.2013.01.014

Thurber, S., Snow, M., \& Honts, C. R. (2002). The zung self-rating depression scale convergent validity and diagnostic discrimination. Assessment, 9(4), 401-405.

Uzun Ozer, B., O’Callaghan, J., Bokszczanin, A., Ederer, E., \& Essau, C. (2014). Dynamic interplay of depression, perfectionism and selfregulation on procrastination. British Journal of Guidance and Counselling, 42(3), 309-319.

Van Veen, V., \& Carter, C. S. (2002). The anterior cingulate as a conflict monitor: fMRI and ERP studies. Physiology \& Behavior, 77(4), 477-482.

Wang, K., Wei, D., Yang, J., Xie, P., Hao, X., \& Qiu, J. (2015). Individual differences in rumination in healthy and depressive samples: Association with brain structure, functional connectivity and depression. Psychological Medicine, 45(14), 2999-3008. doi:10.1017/S0033291715000938

Wei, D., Du, X., Li, W., Chen, Q., Li, H., Hao, X., ... Qiu, J. (2015). Regional gray matter volume and anxiety-related traits interact to predict somatic complaints in a non-clinical sample. Social Cognitive and Affective Neuroscience, 10(1), 122-128. doi:10.1093/scan/nsu033

Wheeler, H. A., Blankstein, K. R., Antony, M. M., McCabe, R. E., \& Bieling, P. J. (2011). Perfectionism in anxiety and depression: Comparisons across disorders, relations with symptom severity, and role of comorbidity. International Journal of Cognitive Therapy, 4(1), 66-91.

Wirtz, P. H., Elsenbruch, S., Emini, L., Rudisuli, K., Groessbauer, S., \& Ehlert, U. (2007). Perfectionism and the cortisol response to psychosocial stress in men. Psychosomatic Medicine, 69(3), 249-255. doi:10.1097/PSY.0b013e318042589e

Wu, K. D., \& Cortesi, G. T. (2009). Relations between perfectionism and obsessive-compulsive symptoms: Examination of specificity among the dimensions. Journal of Anxiety Disorders, 23(3), 393-400. doi:10.1016/j.janxdis.2008.11.006

Wu, T. F., \& Wei, M. (2008). Perfectionism and negative mood: The mediating roles of validation from others versus self. Journal of Counseling Psychology, 55(2), 276.

Xia, L. X., Ding, C., Hollon, S. D., \& Fan, Q. (2012). The relationship between interpersonal self-support and depression: A longitudinal study. Journal of Social and Clinical Psychology, 31(8), 835.

Xia, M., Wang, J., \& He, Y. (2013). BrainNet Viewer: A network visualization tool for human brain connectomics. PLoS ONE, 8(7), e68910.

Zhu, F., Zhang, Q., \& Qiu, J. (2013). Relating inter-individual differences in verbal creative thinking to cerebral structures: An optimal voxel-based morphometry study. PLoS ONE, 8(11), e79272. doi:10.1371/journal.pone. 0079272

Zi, F., Ma, M., et al. (2010). Studies on perfectionism. Beijing: China Forestry Publishing House.

Zi, F., \& Zhou, X. (2007). The Chinese frost multidimensional perfectionism scale: An examination of its reliability and validity. Chinese Journal of Clinical Psychology, 14(6), 560-563.

Zung, W. W. (1965). A self-rating depression scale. Archives of General Psychiatry, 12(1), 63-70.

Zung, W. W. (1971). A rating instrument for anxiety disorders. Psychosomatics, 12(6), 371-379.

Zuroff, D. C., Blatt, S. J., Sotsky, S. M., Krupnick, J. L., Martin, D. J., Sanislow, C. A., III, \& Simmens, S. (2000). Relation of therapeutic alliance and perfectionism to outcome in brief outpatient treatment of depression. Journal of Consulting and Clinical Psychology, 68(1), 114 